\title{
INSERÇÕES ENUNCIATIVAS, AUTONÍMIA $\epsilon$ SUPPOSITIO SEMANTICA
}

Eugênio Pagotti*

RESUMO: As inserções enunciativas, enquanto tipos particulares de discurso direto, constituem exemplos de estruturas formadas por signos autonímicos: no uso dos signos, distingue-se claramente entre a menção a referentes extralingiuísticos (suppositio formalis) e a menção aos próprios signos (suppositio materialis). Neste trabalho, examinamos um caso intermediário, em que não apenas se torna relevante mencionar autonimicamente o próprio signo, mas também mencionar algum significado específico que o signo deve enfatizar: esses são casos de suppositio semântica.

PALAVRAS-CHAVE: Discurso direto; Inserções enunciativas; Termos autonímicos; Suppositio semântica.

\section{CONSIDERAÇÕES INICIAIS}

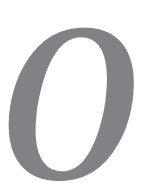

objetivo deste trabalho é verificar a pertinência da leitura autonímica das inserções enunciativas em suppositio semantica, a partir de excertos do material registrado pelo Projeto Nurc/SP.

1. Conforme destacamos em texto anterior, ${ }^{1}$ para a adequada compreensão do caráter semiótico do discurso reportado, é importante distinguir entre duas situações básicas:

Universidade de São Paulo.

Pagotti (2002, pp. 62-100). 
PAGOTTI, Eugênio. Inserções enunciativas, autonímia e suppositio semantica.

a) a presença de signos em uso denotativo extralinguíístico, desempenhando as seguintes funções: i) constituir objetos-de-discurso mediante referenciação; ii) designar objetos-de-realidade mediante referência; iii) mencionar objetos mentais extralinguíísticos (conceitos não-gramaticais); iv) participar de predicações em relação a esses objetos. Como exemplo, temos: [1.1] "São Paulo possui um rio poluído"; [1.2] "O termo médio em um silogismo é comum à premissa maior e à premissa menor" e [1.3] "Santos é litorânea". Em suma, usamos um signo para mencionar algo que não esse signo particular; segundo uma tradição lógica, temos aqui, simplesmente, o uso de um signo;

b) a presença de signos em uso denotativo metalinguístico lato sensu, ${ }^{2}$ isto é, termos que implicitamente desempenham uma função intralinguiística, mencionando a si mesmos, ou seja, tomando a si mesmos como objetos de referência e destacando seus planos de expressão ou estruturas significantes: trata-se, portanto, de signos autonímicos. ${ }^{3}$ Tais signos participam de predicações que de-

2 Os termos metalinguíísticos stricto sensu são criados para expressar os conceitos puramente gramaticais, constituindo o vocabulário técnico dessa metalinguagem. Nessa categoria, temos os termos tais como: "substantivo", "sujeito", "adjetivo”, "adjunto adnominal", etc.

3 "Quando um símbolo é usado (...) como um nome de si mesmo (ou, mais precisamente, como um nome de seu próprio esquema-símbolo), chamá-lo-emos um 'símbolo autônimo"; "Uma designação de um objeto pode ser ou um nome próprio ou uma descrição desse objeto. A evidente necessidade de ter em mente a distinção entre uma designação e o objeto designado (...) embora frequientemente enfatizada em Lógica, não é sempre observada na prática. Se o objeto designado é uma coisa tal como uma cidade, e a designação em si mesma uma palavra (falada ou escrita), a distinção é obvia. (...). Se, em vez de "'Paris' é dissílaba", escrevêssemos "Paris é dissilaba", o método de escrita é incorreto, porque estamos usando a palavra 'Paris' em dois sentidos diferentes"; "Desde que o nome de um dado objeto pode ser escolhido arbitrariamente, é perfeitamente possível tomar, como nome de uma coisa, a coisa em si mesma ou, como o nome de um tipo de coisa, as coisas desse tipo. Podemos, por exemplo, adotar a regra pela qual, em vez da palavra 'fósforo', um fósforo deva sempre ser colocado sobre o papel. Mas é mais frequiente que uma expressão linguística, em vez de um objeto extralinguiístico, seja usada como sua própria designação. Denominamos uma expressão que é empregada desse modo como 'autônima'. Nesse caso, a expressão é usada em alguns lugares como a designação de si mesma e em outros como a designação de outra coisa" (Carnap, 1937, pp. 17,153,156). 
claram atributos desses mesmos signos. Como exemplos, temos: [2.1] "São Paulo possui dois ditongos", [2.2] "O termo médio não poderia ser eliminado do enunciado "1.2"' e [2.3] "Santos é paroxítona". Como é possível perceber, alguma convenção gráfica deve ser utilizada para sinalizar o fenômeno autonímico. Em [2.1], devemos grafar 'São Paulo'; em [2.2], o termo "médio" deve aparecer entre aspas simples ('médio') e em [2.3] o termo "Santos" deve assim ser grafado: 'Santos'. Em suma, na autonímia, usamos um signo para mencionar esse signo em particular, enfatizando seu significante (embora seus significados mantenham-se implícitos, sem destaque especial); segundo uma tradição lógica, temos aqui, simplesmente, a menção a um signo.

A estrutura $[d ; v]$ : " $C$ " da citação direta ${ }^{4}$ pode ser focalizada, dentre outros, a partir de dois pontos de vista concorrentes: a) uma estrutura global de signos em uso denotativo extralinguiístico $E^{\mathrm{n}}\left(C^{\mathrm{n}}\right),{ }^{5}$ isto é $E^{\mathrm{n}}\left(C^{\mathrm{n}}\right)$ :" $E^{\mathrm{n}}\left(C^{\mathrm{n}}\right)$ "; b) uma subestrutura de signos em uso extralinguiístico denotativo e uma subestrutura de signos em uso metalinguiístico lato sensu ou signos autonímicos, ou seja, $E^{\mathrm{n}}\left(C^{\mathrm{n}}\right)$ : “ $E^{\mathrm{n}}\left(E^{\mathrm{n}}\left(C^{\mathrm{n}}\right)\right)$ ”.

4 "A citação direta (...) representa uma estrutura enunciativa cuja fórmula canônica pode ser simbolizada por [d; $v]: ' C$ ', isto é, há uma subestrutura introdutória formada por uma dêixis ' $d$ ' (pressupondo uma relação ego-hic-nunc, que afirma a existência de um determinado locutor, em dado espaço e em dado tempo) e um verbo declarativo ' $v$ ' (a estrutura de apresentação $[d ; v]$ pode ser lida: 'o locutor $A$, no tempo $T$ e no lugar $L$, disse:...'); a essa subestrutura segue um enunciado citado ' $C$ ', visto como uma reprodução literal de um enunciado anterior ou como uma representação mimética cujos signos podem ser entendidos como autonímicos. Os colchetes indicam que essa subestrutura pode ser explícita ou estar implícita, embora seja sempre resgatável ou passível de postulação" (Pagotti, op. cit., p. 16).

5 "Adotaremos aqui a simbologia presente em Barthes (1993, pp. 95-9), em que o plano de expressão ' $E$ ' e o plano de conteúdo ' $C$ ' apresentam-se ligados por uma relação 'R $E R C$ ', formando assim o signo. Os parênteses substituem o símbolo ' $R$ ', indicando a presença interna do plano de conteúdo frente à presença externa do plano de expressão: ' $E^{\mathrm{n}}\left(C^{\mathrm{n}}\right)$ '. $\mathrm{O}$ índice ' $n$ ' indica a presença de um plano de expressão e um plano de conteúdo ambos genéricos, ou seja, referentes a um signo tomado como fórmula ou como representante de toda uma classe ou categoria; números atribuídos ao índice sinalizam a presença de um signo específico. Sempre que anotarmos ' $E^{1}\left(C^{1}\right)^{\prime}$, estaremos fazendo referência a um signo específico, em sua versão extralinguiística denotativa, indicando um significado lexical usual" (Ibid., p. 62). 
PAGOTTI, Eugênio. Inserções enunciativas, autonímia e suppositio semantica.

Esta última situação é aceita por autores que vêem na citação direta stricto sensu um caso de emprego autonímico dos signos, o que implica, portanto, a inexistência de qualquer relação extralinguiística denotativa, sendo enfatizado o caráter metalinguiístico dos signos usados entre aspas, com destaque para os planos de expressão.

Segundo afirmamos em nosso trabalho, é possível interpretar as citações diretas stricto sensu (os enunciados usualmente apresentados entre aspas no discurso reportado) como estruturas autonímicas cujo caráter difere em certa medida do uso autonímico tradicional: constituiriam ocorrências do que se denomina, segundo a proposta de Christensen (1957, pp. 363-7) suppositio semantica . Nesse caso, existe menção intralinguíística denotativa em relação ao próprio signo; porém, menciona-se o plano de expressão e, simultaneamente, o plano de conteúdo, focalizando algum significado específico que o signo deve assumir no contexto de um enunciado particular. Nesse tipo de autonímia, portanto, o significado recebe um destaque que o emprego autonímico tradicional não promove. É o caso do seguinte exemplo: [3] “"Mala' é 'maçador'”.

Estabelecêramos um resumo comparativo entre as características essenciais da subestrutura da citação stricto sensu " $C$ " e o tipo de ocorrência que então identificamos e denominamos "inserção enunciativa”: aqui, interessa-nos lembrar as principais características desta última. ${ }^{6}$

Apresentamos as características da citação stricto sensu: sob o aspecto formal, a citação-inserto "C" apresenta-se como um enunciado cuja função sintática corresponde a um complemento objeto do verbo declarativo da subestrutura introdutória. Quer explícito, quer implícito, o verbo declarativo realiza um enquadramento da citação, que passa a ser tratada como uma estrutura a ele subordinada, sob o aspecto gramatical e discursivo. Uma vez dependente, a citação-inserto é adaptada, de forma a não representar ruptura na organização sintática ante o co-texto. Sob o aspecto dos signos constituintes, entendemos que a citação-inserto "C" é formada por signos autonímicos em situação de suppositio materialis. Porém, essa condição é mascarada pela condição de suppositio formalis dos signos co-textuais, pela influência do enquadramento, e pela influência da estrutura dêitica do locutor principal. Sob o aspecto da conversão em discurso indireto, a citação-inserto normalmente aceita uma conversão para um discurso indireto interpretado como equivalente, ou, mais precisamente, como ambas as 
Formalmente, essa estrutura não depende de qualquer subestrutura introdutória de tipo $[d ; v]$. Não há uma citação-inserto subordinada a um enquadramento co-textual e, portanto, não há a necessidade de acomodações sintáticas em relação aos trechos enunciativos antecedentes e subsequientes. A ruptura sintática é um traço característico do emprego discursivo da inserção enunciativa; sua integração textual verifica-se, portanto, no plano discursivocognitivo.

No que diz respeito aos signos constituintes, verifica-se que essa estrutura é constituída por signos autonímicos em situação de suppositio semantica. O caráter autonímico fica evidenciado, quer pela presença de marcas discursivas que descaracterizam uma possível menção extralinguiística denotativa sobre a qual se predica (suppositio formalis), quer pela impessoalidade, atemporalidade e atopicidade impostas pela estrutura dêitica do enunciado mimeticamente demonstrado (staging). O emprego das inserções enunciativas implica uma ênfase não só sobre a estrutura de significantes, mas também sobre alguns significados específicos, fato que justifica a leitura em suppositio semantica.

Sob o ponto de vista enunciativo, a inserção enunciativa não apresenta uma dêixis subordinada, discursivamente, à estrutura dêitica do locutor principal, isto é, nenhuma imbricação dêitica é

formulações são consideradas correspondentes, aceita-se que qualquer citação possa ser formatada em discurso direto ou indireto, indiferentemente, desde que se privilegie uma leitura "de re" do enunciado a ser reportado. Sob o aspecto discursivo, a citação-inserto corresponde a uma enunciação organizada de acordo com estruturas dêiticas debreadas pelo locutor que reporta, as quais tomam como referência básica a própria situação enunciativa desse locutor. O locutor pode interferir e determinar efeitos discursivos (modalizações, evidencialidade, envolvimento, etc.) que se estabelecem entre ele, os enunciadores instalados na citação-inserto e seus interlocutores da interação atual. A presença do verbo declarativo impõe, explicitamente, uma seleção de perspectivas e pontos de vista; mesmo assim, a citação-inserto é, convencionalmente, assumida como uma reprodução neutra e fiel do enunciado citado. A função discursiva por excelência da citação-inserto é, real ou imaginariamente, reproduzir um enunciado-fonte anterior, do mesmo modo que, em uma paráfrase, o texto-produto representa um enunciado semanticamente equivalente ao texto-fonte. 
PAGOTTI, Eugênio. Inserções enunciativas, autonímia e suppositio semantica.

manifestada de modo explícito. Propriamente falando, dever-se-ia assumir aqui a existência de uma estrutura dêitica virtual que se mantém indefinida, sem preenchimento semântico específico. A posição do locutor em relação à inserção enunciativa depende, sobretudo, de operações inferenciais realizadas pelo interlocutor; manifesta-se, simplesmente, a ação elocutória em si mesma, ocultando-se a polarização entre locutor-enunciador, típica da citação direta.

Com base nessa síntese, identificamos o objeto em questão. Trata-se de: a) uma estrutura de signos autonímicos em suppositio semantica; b) uma demonstração enunciativa por staging, ou seja, uma representação mimética de um enunciado potencial, caracterizando uma "cena enunciativa" ou "cenografia"; c) um enunciado que não depende de qualquer estrutura de enquadramento do tipo [d; v]; d) uma inclusão co-textual cuja coerência se verifica no plano discursivo-cognitivo; e) uma estrutura dêitica impessoal, atópica e atemporal. É interessante comparar esse objeto com aquilo que, em Koch (2004, p. 78), denomina-se "categorização metaenunciativa de um ato de enunciação".

2. Para nossos objetivos, importa retomar Christensen (op. cit., pp. 363-67) e examinar o conceito, proposto pelo autor, de suppositio semantica. Os exemplos que apresenta são: [4] "Você nunca deveria dizer "nunca”"; [5] “'Oftalmologista' significa o mesmo que 'médico de olhos"”.

No exemplo [4], temos um enunciado que obviamente menciona um objeto linguiístico. O signo "nunca" (primeira ocorrência) representa um uso cuja menção é extralinguiística e denotativa: trata-se de um caso de suppositio formalis, pelo qual o signo desempenha sua função canônica - promover uma referência ou uma referenciação. Por sua vez, o signo “"nunca”' (segunda ocorrência) aparece entre aspas simples, acompanhando a convenção lógica sobre os autonímicos, constituindo uma ocorrência em suppositio materialis. Porém, percebe-se aqui uma particularidade: não há, uni- 
camente, uma menção à estrutura significante para se dizer algo a respeito dela: há também uma menção a um significado específico que esse signo deve assumir, menção essa simultânea à demonstração mimética do signo enquanto puro significante.

Em outras palavras, o que nunca se deveria dizer não é simplesmente o significante "nunca" (/'nũ.kə/), mas sim, e isto é decisivo, esse significante com um significado particular (por exemplo, “jamais"). Ou seja, o enunciado deixa claro que o locutor está também enfatizando o conteúdo semântico do signo e não apenas sua estrutura de significantes em suppositio materialis. Contudo, deve-se observar que este, igualmente, não é um uso para mencionar, como ocorre em suppositio formalis, um significado extralinguístico sobre o qual se predica ou um uso para designar um dado referente. Segundo o autor, trata-se de uma terceira modalidade de suposição, para a qual propõe a denominação "suppositio semantica".7

Para o exemplo [5], observa-se que 'oftalmologista' e 'médico de olhos' não ocorrem como signos mencionados unicamente em suas estruturas significantes: são menções que focalizam o signo integral, com seus significados definidos, embora não se refiram a qualquer oftalmologista materialmente dado, nem tampouco a algum

\footnotetext{
'Considere, por exemplo, a sentença - 'Você nunca deveria dizer 'nunca' -; não há dúvida que nessa sentença falamos sobre algo linguiístico. Por essa razão 'nunca' está colocado entre aspas simples, de acordo com as convenções costumeiras. Por outro lado, é igualmente claro que 'nunca' não é aqui um mero complexo de sons e letras, o qual produzimos para dizer alguma coisa sobre ele. Portanto, deveríamos perguntar se 'nunca' nessa ocorrência deveria ser considerado como parte de um nome mencionando uma expressão linguiística, conforme a visão costumeira o fará. (...) Em [4] é muito claro que a primeira e apenas a primeira ocorrência de 'nunca' deve ser classificada com sento em suppositio formalis, mas não é por isso evidente de imediato que a segunda ocorrência é em suppositio materialis, embora ela seja geralmente classificada assim. Definitivamente, não é o signo material 'nunca' que não deveríamos 'dizer'; ao contrário, é a expressão ou palavra com aquele significado preciso. Parece que necessitamos de um nome para um terceiro tipo de uso aqui, e, desde que o significado é a questão, eu proponho chamá-lo 'suppositio semantica' (...) fazemos nossa tríplice distinção entre diferentes tipos de uso de uma expressão: uso para referir [suppositio formalis], uso como um simples complexo de sons e letras [suppositio materialis], e uso como uma expressão representada com significado" (Christensen, op. cit., p. 365).
} 
PAGOTTI, Eugênio. Inserções enunciativas, autonímia e suppositio semantica.

médico identificável. Há, pois, outro caso da ocorrência denominada suppositio semantica.

De acordo com essa proposta, conclui-se que as expressões linguiísticas podem desempenhar três tipos de uso e menção:

a) um uso que se refere predominantemente ao significante de um signo, mencionando-o em uma predicação (suppositio materialis). Exemplos: [6.1] “'Cão' possui um fonema nasal”; [6.2] "'Cão' pode certamente ser pluralizado" (ou seja, o termo "cão");

b) um uso que se refere predominantemente ao referente (objeto-de-realidade, objeto-de-discurso ou objeto mental) de um signo, mencionando-o em uma predicação (suppositio formalis). Exemplo: [7.1] "Cão possui um olfato aguçado"; [7.2] "Cão pode certamente ser feroz" (ou seja, o animal denominado "cão");

c) um uso que se refere igualmente ao significante e ao significado de um signo, mencionando-o em uma predicação (suppositio semantica). ${ }^{8}$ Exemplo: [8.1] "'Cão' é equivalente a 'o melhor amigo do homem”; [8.2] “"Cão' pode certamente ser 'canídeo”" (ou seja, o signo “cão").

Essa tipologia mostra-se mais acurada, por melhor distinguir ocorrências que, usualmente, seriam incluídas sob uma única rubrica ou constituiriam casos fronteiriços. $\mathrm{O}$ autor observa que a suppositio semantica também não se baseia em uma distinção exclusiva entre uso e menção (a idéia de que ou deveremos usar uma expressão linguiística para falar dos objetos extralinguiísticos referenciados ou deveremos, caso quisermos dizer alguma coisa a respeito dessa expressão, mencioná-la por meio de um nome ou uma descrição metalinguiística).

Assim, a expressão "médico de olhos", no exemplo [5], não é usada como um nome que menciona uma expressão linguíística, isto

Assim resume o autor esta tipologia: "em geral, parece que qualquer expressão lingüística pode ser usada ou ocorrer em, pelo menos, três possibilidades: como um complexo sonoro-gráfico exclusivamente, em suppositio materialis; como uma expressão com significado, mas não referencial, em suppositio semantica, e como uma expressão referencial em suppositio formalis." (Christensen, op. cit., p. 364). 
é, como um signo de um signo (como ocorreria no seguinte exemplo: [9] “"Médico de olhos' pode ser pronunciado com cinco sílabas"); é um uso demonstrativo dessa expressão para mostrar o significado do signo "oftalmologista". Em suma, a expressão "médico de olhos" é mencionada e demonstrada (mimeticamente representada mediante staging) não apenas como um complexo sonoro e gráfico de significantes (suppositio materialis), mas sim como um complexo semiótico dotado de um significado e uma função significativa particular.

O quadro abaixo, adaptado de nosso já mencionado trabalho, presta-se para ilustrar os três tipos de suposição aqui tratados: na primeira coluna, temos exemplos de suppositio formalis, nos quais os termos empregados designam referentes extralinguiísticos (objetosde-realidade) ou constituem objetos-de-discurso; na coluna central, temos exemplos de suppositio materialis, nos quais os termos sublinhados dizem respeito a objetos estritamente linguiísticos, subentendendo estruturas introdutórias tais como "a palavra" ou "a expressão"; por fim, na coluna da direita, aparecem exemplos de suppositio semantica, nos quais os termos sublinhados referem-se, ao mesmo tempo, ao signo enquanto significante e significado, porém sem ser empregado para designar objetos extralinguiísticos por referência ou por referenciação.

\begin{tabular}{|c|c|c|}
\hline suppositio formalis & suppositio materialis & suppositio semantica \\
\hline $\begin{array}{l}\text { [10.1] "Eu gosto de usar essa } \\
\text { expressão radical" } \\
\text { [10.2] "O radical tem uma } \\
\text { conotação negativa hoje em } \\
\text { dia" } \\
\text { [10.3] "Raiz não pode ser } \\
\text { confundida com radical" }\end{array}$ & $\begin{array}{l}\text { [11.1] "Eu gosto de usar essa } \\
\text { expressão 'radical"' } \\
\text { [11.2] "O 'radical' tem uma } \\
\text { conotação negativa hoje em dia" } \\
\text { [11.3] "'Raiz' não pode ser } \\
\text { confundida com 'radical"' }\end{array}$ & $\begin{array}{l}\text { [12.1] '"Radical' quer dizer } \\
\text { 'republicano de esquerda' e não } \\
\text { 'extremista"' } \\
\text { [12.2] '"Radical' é 'aquele que } \\
\text { pensa radicalmente a sociedade"' } \\
\text { [12.3] "Um espírito crítico que se } \\
\text { torna 'radical'; quer dizer, 'pega as } \\
\text { coisas pela raiz"' }\end{array}$ \\
\hline
\end{tabular}

No exemplo [10.1], o signo "radical" é usado em suppositio formalis como adjetivo, mencionando os conceitos "fundamental", "essencial", "básica" que qualificam o termo "expressão". No exemplo 
PAGOTTI, Eugênio. Inserções enunciativas, autonímia e suppositio semantica.

[10.2], "radical", em suppositio formalis como substantivo, menciona o conceito "pessoa não moderada e inflexível", para o qual se predica "conotação negativa", ou seja, "que está vinculado a um valor negativo ou que é membro de uma relação negativa". O exemplo [10.3] mostra que os termos sublinhados referem-se aos conceitos mencionados (ou, em outra perspectiva, aos objetos-de-discurso "raiz" e "radical").

No exemplo [11.1], o signo de signo 'radical' usado em suppositio materialis, mencionando o signo "radical", introduzido pelo termo metalinguiístico "essa expressão". No exemplo [11.2], 'radical', em suppositio materialis, possui como predicado "uma conotação negativa", isto é, "um significado subjacente negativo". O exemplo [11.3] mostra que o exemplo [10.3] pode ser interpretado autonimicamente (trata-se das palavras "raiz" e "radical").

Os exemplos [12.1; 12.2 e 12.3] ilustram casos de suppositio semantica; neles, 'radical' é destacado em seu significante e em um significado específico, fato demonstrado pelas expressões que se prestam para particularizá-lo em uso: assim, 'radical' aqui deve ser compreendido como 'republicano de esquerda'; 'aquele que pensa radicalmente a sociedade'; 'aquele que pega as coisas pela raiz', e não como 'extremista'. Não se trata de suppositio formalis porque, nesses casos, os signos não mencionam conceitos extralinguiísticos em enunciados que exclusivamente predicam em relação a tais referentes: aqui, predica-se, ao mesmo tempo, em relação aos significantes e a certos significados específicos.

Como se pode apreender nesses últimos exemplos, ocorre um processo parafrástico que difere do processo apontado para os termos autonímicos apresentados nos exemplos "11.1", "11.2" e "11.3": não se trata aqui de se encontrar expressões alternativas para descrever um signo através de sua estrutura de significantes, mas sim de encontrar signos que possam ser vistos como equivalentes sob o ponto de vista de significados discursivamente especificados, embora não em uso extralinguiístico denotativo.

Com isso, entendemos que a suppositio materialis e a suppositio semantica representam duas modalidades de autonímia, ambas 
concernentes à utilização intralinguiística dos signos: a primeira denominando os usos nos quais ocorre menção aos significantes, sem menção a significados particularizados (a razão para o uso fundamenta-se na necessidade de se destacar o plano de expressão), e a segunda denominando os usos nos quais ocorre menção aos significantes e a significados específicos (a razão para o uso fundamentase na necessidade de se destacar, ao mesmo tempo, ambos os planos).

3. Examinaremos em seguida alguns excertos para confirmar a pertinência dos conceitos apresentados. Neles, procuraremos destacar exemplos de inserções enunciativas cujo caráter autonímico dos signos em suppositio semântica seja manifesto.

\section{[EXCERTO UM]}

\footnotetext{
L2 eu normalmente ouço também ... -- sabe que pobre levanta cedo né? ((risos)) -- dez para as seis seis horas eu estou ouvindo o noticiário da Tupi... eles dão ... e tem a mãe também né? ... aquela previsão infalível né? sua mãe né? ... "leva guarda-CHUva vai chover olha o céu como é que está" ... é certeza que chove sabe que

90 geralmente mãe não erra né? ... você nunca leva ... entende? ... é fogo você não pode se você for se guiar ... serviço de metereologia ninguém acerta ... você vê o
}

[PROJETO NURC/SP INQUÉRITO No 62 - BOBINA No 20 - INFS. No 69 E 70 - DIÁLOGO ENTRE DOIS INFORMANTES (D2) - LINHAS 84-93]

No primeiro excerto, podemos observar a presença de uma metapredicação com inserção enunciativa: previsão infalível @ "leva guarda-CHUVA vai chover olha o céu como está". A enunciação inserida funciona como uma paráfrase enunciativa da expressão em suppositio formalis "previsão infalível", demonstrando, por meio de mimese e staging, conteúdos semânticos equivalentes. Parece razoável entender que os signos presentes na inserção enunciativa são autonímicos, pois se trata de um uso de signos para mencionar não um referente extralinguiístico, mas sim a própria estrutura semiótica (são essas 
PAGOTTI, Eugênio. Inserções enunciativas, autonímia e suppositio semantica.

palavras específicas que são objetos de menção, e não os possíveis referentes dessas palavras); por outro lado, não podemos deixar de considerar que essas palavras não foram inseridas apenas para mencionar os respectivos significantes, mas sim para também destacar determinados significados. Portanto, entendemos aqui a presença de signos em suppositio semântica, de acordo com a proposta de Christensen.

Para os próximos dois exemplos são válidos os mesmos comentários: no excerto dois temos a estrutura condenar @ “você...católica...numa escola protestante"; no excerto três temos a estrutura ficar analisando@ "olhe mas que coisa". Ambas as inserções podem ser interpretadas adequadamente como casos de suppositio semântica.

\section{[EXCERTO DOIS]}

335 na escola... não é? o que havia era um culto diário... que nós éramos obrigados a assistir... ó que aliás era muito bom... porque era um trechinho da Bíblia... e foi... justamente uma coisa que... al/ na ocasião... algumas

pessoas condenavam "você... católica... numa escola

340 protestante" não tinha importância nenhuma porque eu não sofri influência nenhuma de/ desse protestantismo... e

PROJETO NURC/SP INQUÉRITO No 242 - BOBINA No 92 -INF. No 295 - DIÁLOGO ENTRE INFORMANTE E DOCUMENTADOR (DID) - LINHAS 338-341]

\section{[EXCERTO TRÊS]}

$$
\begin{aligned}
& \text { modernas porque aquelas igrejas antigas... hoje eu até... } \\
& \text { me aborreço quando eu vou visitar de ver TOdo mundo } \\
& \text { fazendo da igreja um museu... então desapareceu a } \\
& \text { religiosidade... todo mundo fica "olhe mas que coisa" } \\
& \text { analisando... as peças... analisando então não é mais um } \\
& \text { ambiente religioso não é? é um ambiente art ístico... }
\end{aligned}
$$

PROJETO NURC/SP INQUÉRITO No 242 - BOBINA No 92 - INF. No 295 - DIÁLOGO ENTRE INFORMANTE E DOCUMENTADOR (DID) - LINHAS 651-656] 
Filol. lingüíst. port., n. 8, p. 97-111, 2006.

\title{
[EXCERTO QUATRO]
}

\author{
$1510 \mathrm{~L} 1$ ai veio uma SÉrie de filmes sobre aquilo ... até parece \\ que às vezes eles poxa vida eles em em virtude das \\ próprias dificuldades financeiras "não pô vamos aproveitar \\ o mesmo cenário tudo aquilo"... agora já facilita né? ... \\ pode pensar nesses termos mesmo ... \\ [PROJETO NURC/SP INQUÉRITO No 62 - BOBINA N 20 - INFS. No 69 E \\ 70 - DIÁLOGO ENTRE DOIS INFORMANTES (D2) - LINHAS 1510-1514]
}

No quarto excerto, temos duas estruturas semanticamente relacionadas: "até parece que às vezes eles poxa vida eles em em virtude das próprias dificuldades financeiras" e "não pó vamos aproveitar o mesmo cenário tudo aquilo". A especificação da primeira estrutura é promovida pela inserção enunciativa seguinte, cujo caráter demonstrativo-mimético, mediante staging, pode ser verificado. Vemos que a leitura em suppositio semantica é a mais razoável: ao mencionar a estrutura "vamos aproveitar o mesmo cenário", o enunciador não se refere a objetos extralinguiísticos contextualizados (a qual cenário se refere o enunciado?), tampouco apenas se refere à sequiência de significantes (não há termos autonímicos em uso metalinguístico lato sensu; comparemos com o seguinte enunciado: "Vamos aproveitar 'o mesmo cenário", em que se subentende a proposta de aproveitamento da expressão "o mesmo cenário"). Destaca-se o significado dessa estrutura como um tipo de paráfrase enunciativa da estrutura anterior ("em virtude das próprias dificuldades financeiras"), constituindo assim um caso de suppositio semântica.

[EXCERTO CINCO]

L2 não é verdade? então eles têm que telefonar... de um

modo que não seja::.... de jeito nenhum seja seja identificado para que que é... e conversar com a pessoa diretamente... e agora normalmente também para chegar nessas pessoas... tem uma série de barreiras... porque não são pessoas que direto "eu quero falar com o Zé de Silva" e o Zé da Silva atende do outro lado... né? tem::...

$1060 \mathrm{~L} 1$ o secretário da secretária

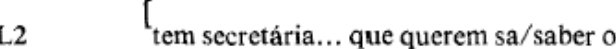
porquê:: o motivo que quer falar com aquela pesso::a tudo isso... né?... então ou ligam para a casa... da

[PROJETO NURC/SP INQUÉRITO Nº 360 - BOBINA No 137 - INFS. Nº 472 E 473 - DIÁLOGO ENTRE DOIS INFORMANTES (D2) - LINHAS 1053-1063] 
PAGOTTI, Eugênio. Inserções enunciativas, autonímia e suppositio semantica.

No quinto excerto, vemos a estrutura em suppositio formalis "também para chegar nessas pessoas ...tem uma série de barreiras...porque não são pessoas que direto (...) e o Zé da Silva atende do outro lado"; como inserto, aparece uma estrutura em suppositio semantica: "eu quero falar com o Zé da Silva”. As mesmas observações anteriores são aqui válidas: não se trata do mesmo uso extralinguiístico verificado co-textualmente; ao mesmo tempo, o significado linguiístico da expressão mencionada é levado em conta, embora não haja menção a referentes contextualmente determinados.

Finalmente, nos próximos dois exemplo, as estruturas "eu vou ser médico", "ah mas lixeiro não" e "vou fazer um sanduíche" podem ser interpretadas como outros casos de suppositio semântica.

\title{
[EXCERTO SEIS]
}

\author{
o que faz um médico... porque às vezes uma criança \\ 60 quando a gente orienta... ela é levada... a... ela gosT Aria \\ de ser lixeira... gosTAria... mas ela não pelo pai \\ pela mãe não "eu vou ser médico"' então ela às vezes \\ vai ser um PÉssimo médico quando ela poderia ser

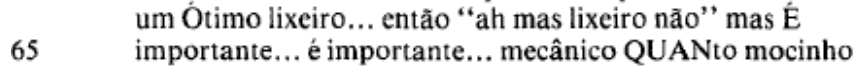 \\ PROJETO NURC/SP INQUÉRITO No 251 - BOBINA No 90 - INF. No 288 \\ - DIÁLOGO ENTRE INFORMANTE E DOCUMENTADOR (DID) - LINHAS \\ 59-65]
}

\section{[EXCERTO SETE]}

Doc. escuta R. vamos supor que você estivesse na sua casa... morrendo de fome... então se você "vou fazer um sanduiche"'... que tipo de sanduiche você faria? o que você lo/ colocaria dentro do PÃO?..

PROJETO NURC/SP INQUÉRITO No 235 - BOBINA No 88 - INF. No 282 - DIÁLOGO ENTRE INFORMANTE E DOCUMENTADOR (DID) - LINHAS 483-486] 
Filol. lingüíst. port., n. 8, p. 97-111, 2006.

\section{CONSIDERAÇÕES FINAIS}

Podemos concluir que, de acordo com os exemplos apresentados, a proposta conceitual de Christensen mostra-se consistente: as inserções enunciativas examinadas possuem não apenas caráter autonímico, mas também desempenham uma função semântica intermediária: não são casos de exclusiva autonímia nem tampouco casos de referencialidade extralinguiística absoluta. A observação dos exemplos aqui apresentados corrobora as análises apresentadas em nosso trabalho anterior, apontando para a pertinência dessa proposta teórica.

\section{BIBLIOGRAFIA}

BARTHES, Roland (1993). Elementos de semiologia. 10. ed. São Paulo: Cultrix.

CARNAP, Rudolf (1937). The logical syntax of language. London: Routledge \& Kegan Ltda. CHRISTENSEN, Niels Egmont (1957). "The alleged distinction between use and mentions" In: Philosophical Review. v. LXXVI, n. 3.

$\mathrm{KOCH}$, Ingedore Grunfeld Villaça (2004). Introdução à lingüística textual: trajetória e grandes temas. São Paulo: Martins Fontes.

PAGOTTI, Eugênio (2002). Uma análise cognitivo-discursiva das metapredicações de identidade com inserções enunciativas. 241 p. Dissertação (Mestrado em Filologia e Língua Portuguesa). Universidade de São Paulo - USP. São Paulo.

ABSTRACT: As a particular kind of direct speech, enunciative insertions represent instances of autonymous sign structures: in usage, one clearly discriminates between mention of extralinguistic referents (suppositio formalis) and mention of the signs themselves (suppositio materialis). In this paper, we examine an intermediate case, in which not only is it relevant to mention autonymously the sign itself, but also to mention some specific meaning that this sign must emphasize: these are cases of Suppositio semantica.

KEYWORDS: Direct speech; Enunciative insertions; Autonymous words; Suppositio semantica. 